\title{
The fastest way to the cecum
}

\author{
CHRISTOPHER B WILLIAMS, BM, FRCP
}

CB Williams. The fastest way to the cecum. Can J Gastroenterol 1993; 7(6): 482-484. Successful colonoscopy requires both an understanding of the common problems encountered in the process of routine examinations and the various solutions to ensure a thorough, quick and painless examination. The colonoscopist is encouraged to be flexible in his approach to advancing the colonoscope and to use the patient's response, as well as the 'feel' of the colonoscope in the patient. Specific anatomical considerations of the colon are discussed with regard to successful passage of the colonoscope. Strategies for straightening and torquing the colonoscope, application of abdominal pressure and patient positioning are detailed. The methods of a forceful versus a technical approach are compared and contrasted. The need to attempt several manoeuvres rapidly, rather than persist in repeated unsuccessful attempts, is stressed.

Key Words: Colonoscopy, Sigmoid colon, Technique

\section{Accès rapide au caecum}

RÉSUMÉ: Pour réussir la colonoscopie, il faut bien comprendre les problèmes susceptibles de survenir fréquemment lors des examens de routine et leurs solutions diverses pour assurer un examen le plus complet, rapide et indolore possible. Le médecin qui pratique la colonoscopie doit préférablement exercer une certaine souplesse lorsqu'il pousse le colonoscope, bien interpréter les réactions du patient et "sentir" la progression de son instrument. Certaines considérations anatomiques du côlon sont abordées relativement au passage sans heurt du colonoscope, appliquer une pression sur l'abdomen, et positionner le patient. Les méthodes vigoureuses sont comparées aux méthodes plus techniques. On insiste sur le manoeuvres successives rapides qui sont privilégiées, au détriment d'une approche répétée et plus insistante.
$\mathrm{S}$ PEED IN PASSING THE COLONO. scope isn't everything, but it helps. It helps the patient by staying within the 4 to 5 min plateau of the maximum effects of intravenous medication and minimizes the autonomic side effects of prolonged endoscopic struggle. Reasonable speed helps in scheduling patient throughput, while minimizing the mechanistic parts of the examination allows more time for care in diagnosis or performing multiple polypectomies. Personally speaking, I am more inter- ested in patient comfort while using modest sedation (intravenous midazolam $2.5 \mathrm{mg}$ with intravenous pethidine 25 to $50 \mathrm{mg}$ ) than in absolute speed, although a quick, painless, accurate examination is the obvious ideal.

\section{BE RELAXED - FEEL THE ENDOSCOPE, LISTEN TO THE PATIENT}

As in most mechanical or sport pursuits greater success comes with operator relaxation, reflex responses and sub-
St Marks Hospital for Diseases of the Rectum and Colon, London, United Kingdom

Correspondence: Dr CB Williams, St Marks Hospital for Diseases of the Rectum and Colon, City Road, London ECIV 2PS, United Kingdom tle awareness, rather than with a tense or tough approach. Standing comfortably, holding the instrument shaft gently (in the fingers rather than the fist) and training the left hand to spin the control wheels easily and accurately to their maximum extent contributes significantly to a facile procedure.

The endoscopist should be aware that a shaft that requires force to push or twist, or controls that feel stiff, indicate that the instrument is looped and should be straightened. A patient in pain is giving the same feedback; ignoring the protest or suppressing it with medication means that a loop is being ignored. An endoscopist who expects to use force gets in the habit of accepting such loop formation and so works at increasing mechanical disadvantage as the insertion continues.

\section{ANATOMIC CONSIDERATIONS IN THE SIGMOID}

The considerable variability of colon length and attachments means that there is no one strategy for speedy insertion. In a patient with a capacious colon, as judged by the feel of the sigmoid colon during insertion or the results of a previous endoscopic or barium contrast examination, the best plan may be to accept formation of a sigmoid colon alpha loop (1), even encouraging such a loop by pushing in the shaft with simultaneous anticlockwise twist; the instrument will run up through the descending colon to the splenic flexure at $90 \mathrm{~cm}$ before being straightened back. The difficulty is that, as often as not, the wished for 'alpha' does not materialize and all that results is forceful bowing-up of the sigmoid into an ' $n$ ' loop, with a fearsome iatrogenic hairpin bend resulting at the sigmoid-descending colon junction. 
In Western patients, the 'crash and dash' approach may sometimes work up to the splenic flexure but generally causes unacceptable pain or equivalently heavy sedation requirements. Oriental patients seem to have more permissive colon attachments and better visceral pain threshold so that twoman insertion technique and well-tolerated loop formation are the norm. The shorter, more muscular and less tolerant Western sigmoid colon is ideally passed with the instrument 'straight' into the sigmoid colon using repeated shortening withdrawals. The process starts once the instrument has reached the mid- or proximal-sigmoid colon, withdrawing before the tip reaches into the descending colon so that the mechanical disadvantage of trying to progress with a hooked or overangled tip is avoided. Since the sigmoid colon spirals clockwise round the pelvic brim into the descending colon, a clockwise corkscrew twist applied to the shaft often helps. Deflation and assistant hand pressure over the lower abdomen also contribute usefully to the shortening process (2). The main paradox in this 'straight endoscope' approach is that hurrying or aggression end up by re-forming the sigmoid loop and losing the subtlety, comfort and subsequent speed of keeping the instrument straight. Obsessional concentration on the minutiae of the close-up view of the anatomy of a bend are particularly necessary when the attachments are mobile and the endoscopist is chasing the mobile target of the approach to the descending.

Flexible endoscopy requires a flexible approach, however, so that after three to four failed attempts to reach around the sigmoid-descending colon junction using subtlety and a straight endoscope (lasting perhaps 1 to 2 mins), it may be best to warn the patient of aggressive intent and then try to 'push through' into the distal descending colon. If this fails or is too painful I ask the patient to rotate to the right lateral position, as gravity sometimes favourably improves the anatomy and transforms the situation at the modest cost of the $30 \mathrm{~s}$ it may require for a sedated patient to rotate.

\section{SPLENIC FLEXURE - HALFWAY HOUSE}

Once in the proximal descending colon or at the splenic flexure, the endoscope can always be straightened back to 40 to $50 \mathrm{~cm}$, and it must be so straightened if the second part of the insertion is to be made easily and quickly. The splenic flexure is a moment of calm for the endoscopist, when the colonoscope cannot slip back excessively (and can be reinserted and actively hooked around the splenic flexure if it starts to do so) and it represents a perfect half-way stage in the procedure. Start the straightening maneuvre by pulling back, then apply active twist to the shaft - usually clockwise, less frequently anticlockwise if the attachments are mobile; occasionally rotation is needed first in one direction and then in the other according to feel and results. When properly straight the endoscope will respond as effortlessly to in/out or twisting movements, as if it were a cue in the hands of a pool player.

\section{POSITION, PRESSURE AND PASSING PROXIMALLY - ALGORITHMS OF COLONOSCOPY}

Any tendency for the sigmoid colon to loop will be exaggerated if the instrument tip meets resistance, as is frequent in passing around the splenic flexure, the midtransverse colon or the hepatic flexure. Using aggressive force is therefore a mistake; it simply loops the instrument and causes pain while getting nowhere. On the other hand, some inward force must be transmitted to the tip. The problem is to combine sufficiently gentle isometric inward pressure to progress without looping the sigmoid while simultaneously steering and coaxing the tip around any particular bend. A useful contribution is made by prestraightening the colon as far as possible by pulling back beforehand and by deflating excess air, particularly in the capacious proximal colon. Since flexures and bends are the main source of friction/resistance, flattening these out by gravity, can also be magical. The splenic flexure (and any fluid in it) almost disappear when the patient is su- pine or in the right lateral position, whereas the hepatic flexure is best traversed in left lateral.

Providing the patient is only lightly sedated, and not too old or infirm, it takes only 20 to $30 \mathrm{~s}$ to roll over completely before the endoscopist passes the instrument shaft under the legs, the small amount of time lost usually being well rewarded by avoiding pain and prolonged attempts to pass a 'difficult' or poorly visualized bend. Adjunctive useful measures include simultaneously twisting the shaft to avoid sigmoid looping and avoidance of over-angling the controls with impaction of the acutely flexed bending section.

Most endoscopists ask for hand pressure by an assistant over the lower abdomen to reduce the degree of sigmoid colon looping, reducing the anteroposterior diameter of the abdominal cavity. Pressure in the upper abdomen to lift the transverse colon or in the left hypochondrium to encourage a downward-looped colonoscope towards the hepatic flexure are also useful routine measures. When the tip will not quite reach to the hepatic flexure after all these efforts have been combined the endoscopist can use 'specific hand pressure' (2), feeling around the abdomen to determine empirically where the assistant can most usefully press.

One of the essentials for rapid colonoscopy is rapidity in trying these various combinations (sometimes repeated several times if necessary), starting with the most predictably logical but working quickly through the alternative measures, picking out and maintaining those actions found empirically to be useful. The number of possible endoscopic options is limited, but the complexity of the decision-making process is simplified and speeded if it is turned into an algorithm of additive, individually logical decisions, rather than thrashing around in an unconstructive, increasingly frustrated and aggressive frenzy.

If, after several attempts, one approach does not work the endoscopist should be thinking of trying another, even its opposite, before resorting to the use of force. Thus, twisting counterclockwise may prove better than the 
usual clockwise torque, especially in the proximal transverse colon, and the right lateral position can sometimes, surprisingly, prove best for passing around an awkward hepatic flexure perhaps because the transverse colon flops downwards.

The endoscopist who is quickest, gentlest, safest and most sure of reaching the cecum needs to be truly a 'flexible' endoscopist, adaptable to circumstance, interested in the minutiae of technique, determined but able to abandon any predetermined scheme if difficulty occurs. The endoscope and the colon can almost invariably and rapidly be finessed into a workable and compatible configuration if the endoscopist concentrates hard and works at it, slowly at first, but faster with experience. There is a logic to colonoscopy but this often means snaking as gently as possible around each successive bend and straightening for the next one without any cast-iron anatomical hypothesis as to what is happening. Speculating as to the position of the instrument tip or the probable configuration of the shaft is of some help in decision-taking, but often proves wrong. When 'lost' in the proximal colon the endoscope is usually in the splenic flexure - the implication being that it should be straightened back to $50 \mathrm{~cm}$ before progress can be made.

\section{PROXIMAL COLON AND ILEOCECAL VALVE}

Total colonoscopy in the 1990s means reaching to the cecal pole, inspecting all of it with positive identification of appendix orifice and the ileocecal valve. Without this rigorous identification of these landmarks it is too easy mistakenly to identify the hepatic flexure as the cecum. Reaching around the hepatic flexure is usually easy, often blindly cranking both controls fully in the appropriate direction, visually predetermined as the instrument first reaches the flexure. Repeated gentle deflation can be used synchronously to collapse and shorten the flexure without losing the view completely.

With a view down the ascending colon a slight asymmetry or inward bulge on the ileocecal valve fold in the distance signals the position of the valve, and this bulge can be accentuated or made to bubble by further deflation. Trying to push may be the worst way of passing down the ascending colon and, as in the duodenum or sigmoid-descending colon, it is usually more productive to pull back the endoscope. This straightens the inevitable transverse colon loop, flattens the hepatic flexure and often causes the instrument tip to slide satisfyingly inwards. Deflation aids the process, position change (supine or prone) may help greatly in reaching the cecal pole and, very occasionally, hand pressure below it can raise the cecum up.

Entering the ileum is mainly a question of identifying the valve, and having the instrument straight (for efficiency of angulation and control) and the colon partially deflated to keep it short and malleable. Thereafter quite fine movements should be sufficient to dip the margin of the colonoscope tip onto the slit of the valve or between its soft lips (appearing as a red-out because of transillumination) then insufflating air to show the granular ileal surface and find the lumen. It helps, as in endoscopic retrograde cholangiopancreatography, to preadjust the instrument by rotation and angling it so that the instrument and valve are precisely aligned for efficient 'cannulation'. Placing the valve in the $6: 00$ position of the endoscope view is ideal since this results in the air nozzle at the lower margin of the instrument tip entering the valve first and facilitates angulation since only the up/down knob is needed for the manoeuvre.

\section{THE 'DIFFICULT' COLON}

Ignoring the obvious problems caused by adhesions after surgery, inflammatory disease or diverticulitis which can occasionally require the use of a pediatric colonoscope (3) or gastroscope - difficulties encountered are usually either the fault of a too rigid and aggressive endoscopist or a too mobile and swingy colon. Endoscopists complaining of regular 'difficulty at the hepatic flexure' have usually not grasped the importance of straightening (to 50 $\mathrm{cm}$ ) the instrument at the splenic flexure and are trying to forge ahead encumbered by a persistent sigmoid colon loop.

A mobile colon can, however, humble the most skilful endoscopist as he, his instrument and the colon thrash around ineffectively. Normal straightening and rotation movements depend on the fulcrum effect of fixed points such as the sigmoid-descending junction or the phrenicocolic ligament which tethers the splenic flexure. In the 5 to $15 \%$ of individuals where intrauterine fusion of the mesocolon or mesentery onto the abdominal wall fails to occur (4) or fixes in odd locations, frustratingly uncontrollable loops may result and none of the 'tricks of the trade' are effective. Nonetheless the cecum can always be visualized (5), even if the instrument will not reach right down into it and the ileocecal valve cannot be entered. It can be a matter of trial and error, rapidly undertaken, as to whether the more aggressive looping 'get it over with' approach is better or whether, as is usually the case, 'shortening and subtlety' are the preferred approach. The reality of colon mobility is reflected in the fact that a colon which proves horrendous to intubate can often, on straightening by withdrawal, be reduced to only 50 to $60 \mathrm{~cm}$ in length. A long but conventionally fixed colon or a short mobile colon can be rapidly examined but a long and mobile colon may be a nightmare even in the best of hands.

\section{REFERENCES}

1. Cotton PB, Williams CB. Practical Gastrointestinal Endoscopy, 3rd edn. Oxford: Blackwell Scientific Publications, 1990.

2. Waye JD, Yessayan SA, Lewis BS, Fabry TL. The technique of abdominal pressure in total colonoscopy. Gastrointest Endosc 1991;37:147-51.

3. Bat L, Williams CB. Usefulness of pediatric colonoscopes in adult colonoscopy. Gastrointest Endosc 1989;35:329-32.

4. Morgenstern L. Persistent descending mesocolon. Surg Gynecol Obstet 1960;110:197-202.

5. Waye JD, Bashkoff E. Total colonoscopy: Is it always possible? Gastrointest Endosc 1991;37:152-4. 


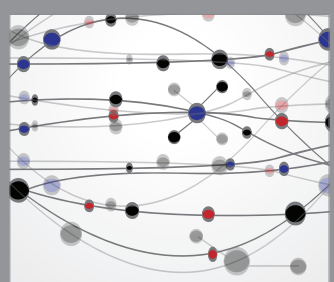

The Scientific World Journal
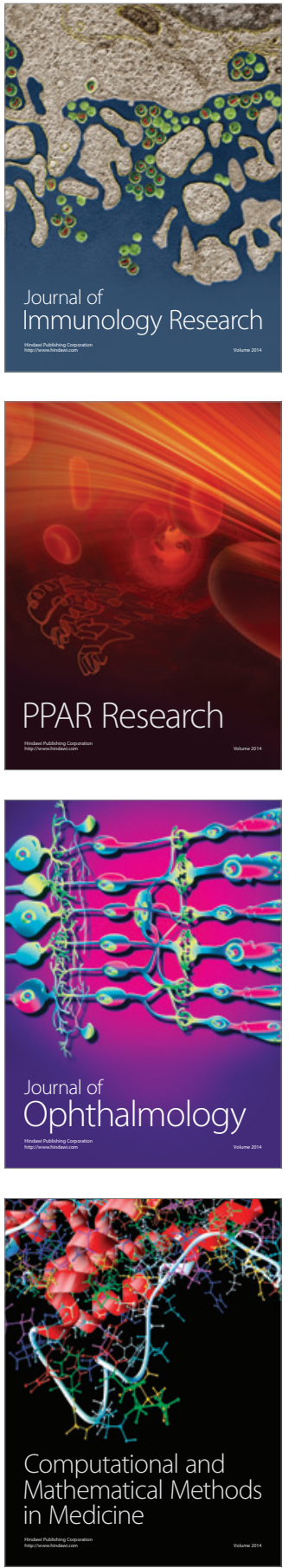

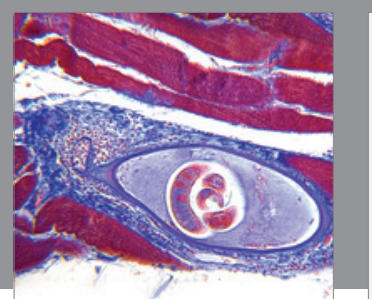

Gastroenterology Research and Practice

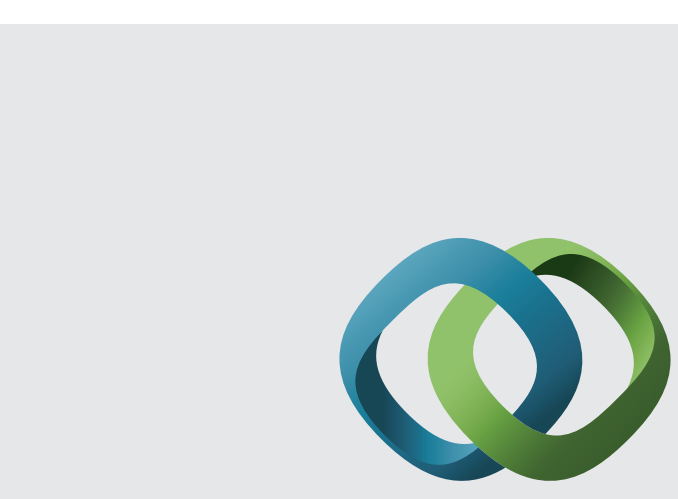

\section{Hindawi}

Submit your manuscripts at

http://www.hindawi.com
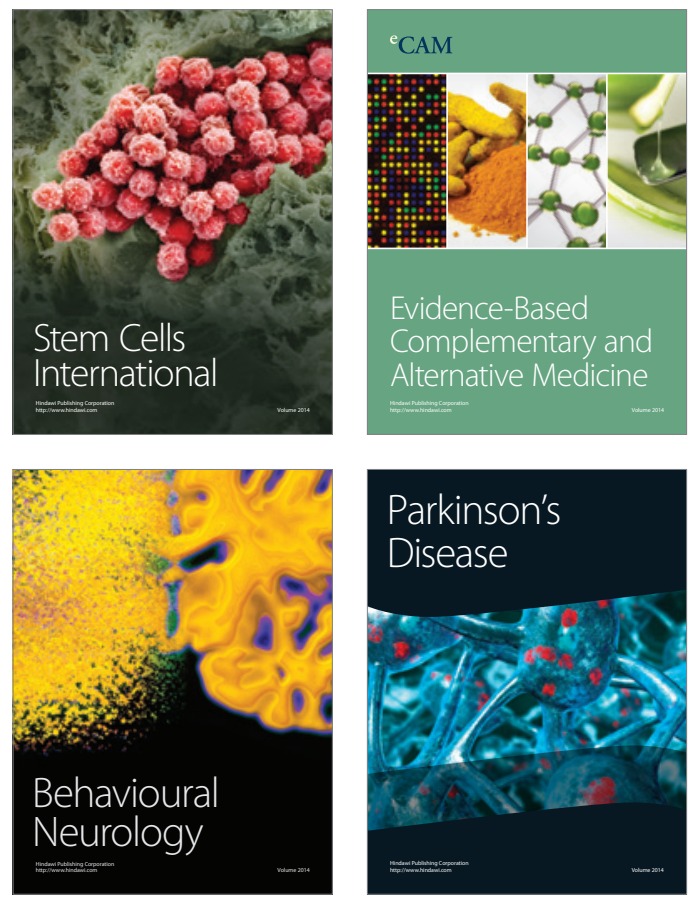
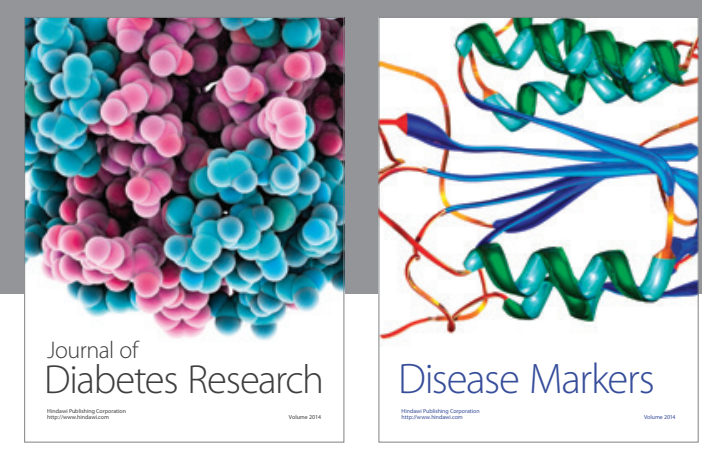

Disease Markers
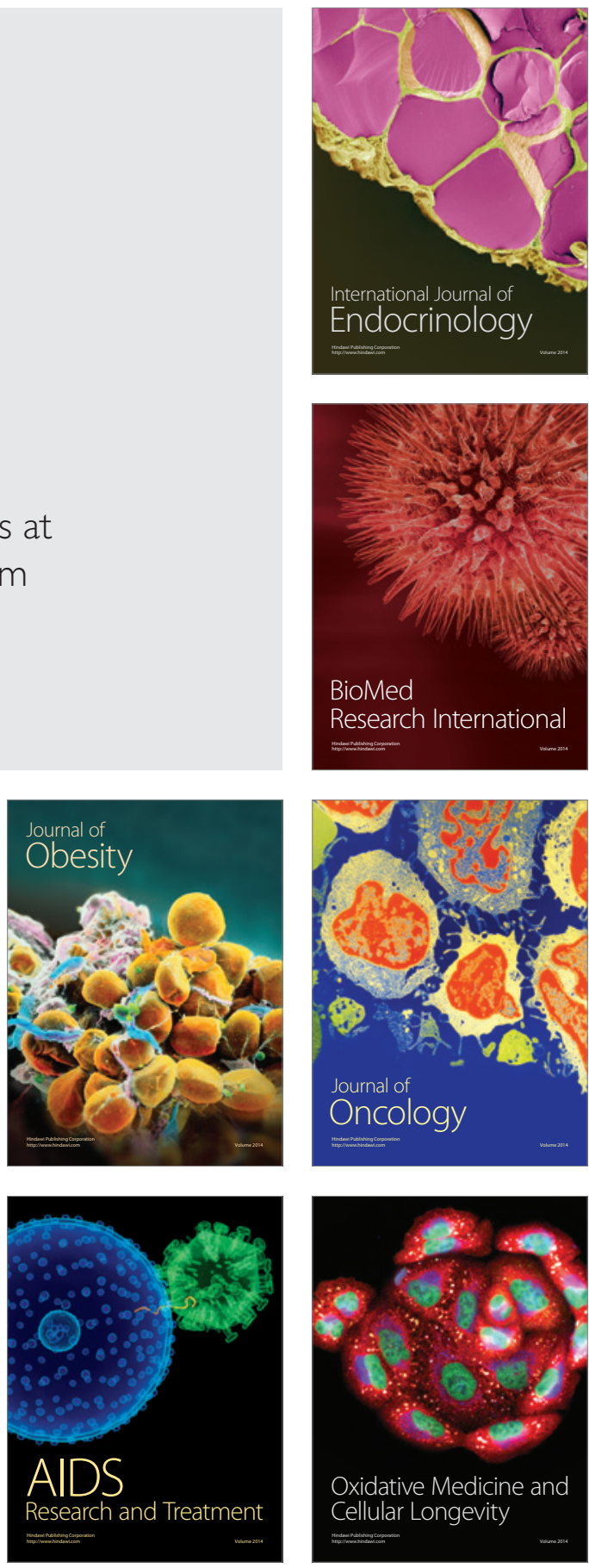